\title{
The effect of psychometric variables in predicting physical activity behavior among diabetes mellitus type-2 patients
}

This article was published in the following Dove Press journal:

Journal of Multidisciplinary Healthcare

I February 2017

Number of times this article has been viewed

\section{Abraham Tamirat Gizaw \\ Fira Abamecha Ababulgu Lakew Abebe Gebretsadik Getachew Kiros Abraha}

Department of Health Education and Behavioral Science, College of Public Health and Medical Sciences, Jimma University, Jimma, Ethiopia
Correspondence: Abraham Tamirat Gizaw

Department of Health Education and Behavioral Science, College of Public Health and Medical Sciences, PO Box 378, Jimma University, Jimma, Ethiopia Email abrishntamirat@gmail.com
Background: Diabetes mellitus type-2 (DMT-2), the most common endocrine disease in the world, is a major global public health-related issue. Diabetes mellitus is one of the most common non-communicable diseases globally, and there is substantial evidence that it is epidemic in many low- and middle-income countries. It is widely recognized that physical activity is important in preventing and treating DMT-2. The aim of this study was to identify predictors of physical activity among DMT-2 patients attending Jimma University Specialized Hospital (JUSH), Southwest Ethiopia.

Methods: A facility-based cross-sectional study was conducted in 2013 at JUSH, Southwest Ethiopia. A systematic random sampling technique was employed to select 322 diabetes patients. Data were collected using a structured questionnaire on interviewer-administered basis. A summary of descriptive statistics, and binary and multiple logistic regression analysis were computed to identify potential predictors of physical activity among diabetes mellitus patients. Results: Among the 319, 70 (21\%) engaged in the recommended physical activity (such as running, jogging, going to the gym, or brisk walking). Two hundred seventy-nine (87.5) of the respondents had adequate general knowledge of diabetes and $31.7 \%$ of the respondents had adequate general knowledge of physical activity. The likelihood of engaging in the recommended physical activity was associated with perceived barrier (odds ratio $[\mathrm{OR}]=0.58,95 \%$ confidence interval, CI [0.56, 0.67]; $p<0.000)$, perceived self-efficacy $(\mathrm{OR}=1.33,95 \%$ CI $[1.12,1.57]$ $p<0.001)$ and perceived benefit ( $\mathrm{OR}=1.16(95 \% \mathrm{CI}[1.03,1.29] p<0.000)$.

Conclusion: This study illustrated that practicing the recommended physical activities among DMT-2 patients was insufficient. Perceived barrier, perceived benefit and perceived self-efficacy became potential predictors of physical activity of DMT-2 patients. None of the socio-demographic factors affect the physical activity behavior of these groups. Diabetes intervention messages should focus on building individual self-efficacy to overcome those barriers with a due emphasis to suggested concrete benefit of physical activity.

Keywords: perceived barriers, self-efficacy, physical activity, diabetes mellitus

\section{Introduction}

Diabetes mellitus (DM) is an endocrine syndrome, constituting a public health problem with a high prevalence of morbidity and mortality. It is one of the most common non-communicable diseases globally, and is classified into two types: diabetic mellitus type-1 (juvenile diabetes), in which the body (pancreas) is unable to produce insulin needed for food energy metabolism; and diabetic mellitus type-2 (insulin resistance diabetes), where the body is unable to utilize insulin effectively. Insulin is the hormone that allows the glucose from food to enter the cells, where it is converted into energy for the proper functioning of muscles and tissues. ${ }^{1}$ 
The prevalence of type-2 diabetes is also increasing rapidly and compromises a major health burden globally. ${ }^{2}$ There are 220 million people living with diabetes mellitus type-2 (DMT-2), worldwide. In most high-income countries, DM is the fifth leading cause of death, and there is evidence showing that it has reached epidemic level in many low- and middle-income countries. ${ }^{3}$ The World Health Organization (WHO) has predicted that the number of adults with DM will rise from 15 million in 2000 to 300 million in 2025 . In 2025 , more than $75 \%$ of the world's diabetic population will be living in developing countries. ${ }^{4,5}$

According to the WHO report, in Ethiopia, the diabetic cases are going to rise from 800,000 (in the year 2000) to 1.8 million by 2030 . However, due to the widening of social differences in economic status, circumstantial evidence shows that the urban population is facing a higher level of overweightness and obesity. ${ }^{6}$

Diabetic self-care practices include behaviors like physical activity, dietary habits, adherence to treatment and avoiding substance use, although the amount of physical activity is decided by each individual. Studies in Ethiopia are limited regarding chronic diseases like DM and physical activity behavior.?

The Canadian Diabetes Association's Clinical Practice Guidelines for the prevention and management of diabetes recommended that type-2 diabetic patients should participate in moderate-intensity physical activity, such as brisk walking and biking, for at least 150 minutes/week, over at least three nonconsecutive days. However, recent studies have shown that diabetic patients may undertake less physical activity than non-diabetic people. The importance of engaging in the recommended physical activity such as self-management behavior is recognized by the majority of the diabetes patients; however, for various reasons, many of these patients do not engage in this physical activity. ${ }^{8}$

Most studies show behavioral changes are needed to achieve the goals of exercise training: to minimize obstacles such as lack of time and negative attitudes towards physical activity. A study also estimated that $37-60 \%$ of diabetics do not perform any exercise. Eighty percent of patients with diabetes suffer from lack of awareness, knowledge and practical skills about physical activity and healthy lifestyle. ${ }^{9,10}$

A study done in Ethiopia on self-care practices of diabetes patients showed that very few patients, 87 (39.2\%), engaged in the recommended self-care practices. Drug adherence and dietary intake were the most frequently used self-care practices, which constitute 174 (78.4\%), and 128 (57.7\%), respectively; however, physical activity was the least practiced. ${ }^{11}$ Another study carried out on self-care practice in
Jimma University Specialized Hospital (JUSH), Ethiopia, indicated that only $20.2 \%$ of respondents reported that they were taking necessary precautions when engaged in exercise they were not used to or "first-time" exercise. Similarly, only $48.5 \%$ walked for $15-30$ minutes per day. ${ }^{12,13}$

\section{Methods}

\section{Study design and setting}

Facility-based cross-sectional study design was employed from March 20 to April 27, 2013 in JUSH. The hospital is located in Jimma City, $357 \mathrm{~km}$ away from Addis Ababa, in the Southwest part of Ethiopia. It is a referral centre for the southwestern part of Ethiopia, and currently, the only teaching and referral hospital in the southwestern part of the country. It provides services for approximately 9,000 inpatient and 80,000 outpatient attendances a year who are visiting the hospital from the catchment population (15 million people).

\section{Sample size and participants}

The source population of the study was all DMT-2 patients attending diabetes clinic of JUSH for follow-up. The sample size was determined and estimated using a single population proportion formula. Assuming the proportion of physical activity among DMT-2 patients as 50\%, 95\% confidence level and $5 \%$ margin of error, the sample size was calculated to be 322 after correcting for population size. A patient was included in the study if he/she was diagnosed as DMT-2 for at least six months and had been part of a follow-up program of JUSH diabetic clinic.

\section{Sampling procedure}

A systematic random sampling procedure was employed to select study participants. Sampling frame was created from patient documents (card). The diabetic clinics provided their services only two days per week. On average, 150 patients with DMT-2 were treated per week, and 600 patients were treated per month. Based on the decision to collect data over the course of one month, the sampling interval was determined by dividing the expected number of DMT-2 patients per month by the sample size of 322 , which gives approximately two. Therefore, an exit interview was done with every other individual patient during the study period.

\section{Data collection tools and measurements}

The questionnaire was prepared in English and then translated into Amharic language (local language) and back translated into English language by another person to check its semantic equivalence. The instrument used contains 
socio-demographic, socio-economic knowledge of diabetes, knowledge of physical activity, cues to action, perceived barriers, perceived benefits and perceived self-efficacy.

The likelihood of engagement in the recommended physical activity was measured using seven items. This was classified as "high recommended physical activity" and "below recommended physical activity". The respondents were labeled to have "high recommended physical activity," if he/she practiced three days per week at least for 30 minutes continuously. Perceived barrier was measured using seven items, perceived benefit using seven items and self-efficacy using seven items.

We measured general knowledge of the respondents on diabetes and physical activity for the management of diabetes complications. Respondents were categorized as having good general knowledge of diabetes and physical activity if they scored above the mean value. Body mass index (BMI) was calculated and classified as underweight, normal weight, overweight and obese. Weight and height measurements were taken during their routine check-up at the health care facilities.

\section{Statistical data analysis}

Subsequently, double data entry was made using Epi-data 3.1 software, and data were analyzed using the statistical package for social sciences (SPSS) software (v 20.0; IBM Corporation, Armonk, NY, USA). A summary descriptive statistics was computed for variables such as socio-demographic data. Logistic regression analysis was applied to describe the functional independent predictors of physical activity. Point estimates of odds ratio (OR) with $95 \%$ confidence interval (CI) were determined to assess the strength of association between independent and dependent variables. For all statistically significant tests, $p<0.05$ was used as a cut-off point. Principal component analysis (PCA) with Varimax rotation greater than 0.4 factor loading was done to identify the emerging dimensions and validate items for advanced regression analysis. Eigen value greater than one was used to retain three factors (Table 1).

\section{Ethical consideration}

The study was ethically approved by the health research and postgraduate coordinating office, College of Public Health and Medical Science of Jimma University. A signed consent (written consent) was obtained from each study participant before each interview, and confidentiality was assured. Reading the consent form to the participants was based on the willingness to participate in the study.

\section{Result \\ Socio-demographic characteristics}

The overall response rate was $99.1 \%$. Among the 319 respondents, 225 (70.5\%) were males and 94 (29.5\%) were females. The mean age of the respondents was $55.3(\mathrm{SD} \pm 5.7)$ ranging from 42 to 65 years. Respondents greater than 55 years old constituted the majority, accounting for 166 (52.0\%).

With regard to the religion, $187(58.6 \%)$ belonged to the Muslim community and 123 (38.6\%) orthodox Christianity. Regarding the occupation, 97 (30.4\%) of the respondents were government employees and 85 (26.6\%) were farmers. The mean average monthly income was 876.5 (SD \pm 62.2 ) Birr or 47.1 USD. Ninety-four (29.5\%) study subjects had a family history of diabetes.

\section{Patients' diabetes history}

The mean duration since being medically diagnosed for diabetes was $4.9(\mathrm{SD} \pm 2.3)$ years. The mean BMI was 22.8 ( $\mathrm{SD} \pm 2.8)$ and most patients, $239(74.9 \%)$, were found to be in the normal weight category (i.e. $\mathrm{BMI}=18.5-24.9$ ), but 68 $(21.3 \%)$ were obese (i.e. $\mathrm{BMI}=25-29.9)$.

\section{Knowledge about DM and physical activity}

The majority of the respondents, 275 (87.5\%), had good general knowledge of DM. An overwhelming majority, 316 (99.1\%), of the respondents were knowledgeable about the classic signs and symptoms of diabetes. About 296 (92.8\%) of the respondents think that it is possible to control or manage diabetes. The majority, 298 (93.4\%), had knowledge

Table I Results of PCA of psychometric dimensions among diabetic type-2 patients in Jimma University Specialized Hospital, Southwest Ethiopia, 2013

\begin{tabular}{|c|c|c|c|c|c|c|}
\hline Number & $\begin{array}{l}\text { Psychometric } \\
\text { dimensions }\end{array}$ & Number of items & Mean士SD & Variance explained in \% & Factor loading & Cronbach's $\alpha$ \\
\hline I & Self-efficacy & 3 & $12.03 \pm 3.57$ & 33.38 & $0.95-0.86$ & 0.72 \\
\hline 2 & Perceived benefit & 5 & $21.53 \pm 2.90$ & 17.15 & $0.82-0.68$ & 0.61 \\
\hline 3 & Perceived barrier & 4 & $15.73 \pm 3.79$ & $|5.7|$ & $0.92-0.60$ & 0.72 \\
\hline 4 & Total & 12 & - & 66.24 & - & - \\
\hline
\end{tabular}

Abbreviations: SD, standard deviation; PCA, principal component analysis. 
of at least one of the complications of diabetes. Regarding physical activity, very few, $31.7 \%$, of the respondents had good general knowledge about the recommended physical activity. Among these, a substantial proportion, 56 (55.4\%), of the respondents reported to have engaged in physical activity three times a week. A many of the respondents, 281 (88.1\%), reported that they perform below the recommended level of physical activity for diabetes patients. A majority of the respondents, $312(97.8 \%)$, replied that it is possible to control diabetes by engaging in physical activity.

The respondents received information from different sources. Accordingly, about 230 (72.1\%) got information about the importance of physical activity for the management of diabetes complications in the last month, of which $215(48.3 \%)$ received information from more than one source. The main sources of information were media and health professionals, which accounted for, respectively, 191 (42.9\%) and $128(28.8 \%)$, and 38 (11.9\%) of the respondents had practiced recommended physical activity for DMT-2 patients (i.e. did specific exercise session for 30 minutes in the last seven days). That meant that 281 (88.1\%) of the respondents had not practiced the recommended physical activity within seven days (a week) of the data collection time. Approximately 46 (14.4\%) did not engage in any activity (like walking for 30 minutes), while the majority, 273 (85.6\%), did not engage in any physical activity.

\section{Independent predictors of physical activity behavior}

Multiple logistic regression analysis was performed with all the significantly associated variables from the bivariate analysis. Accordingly, perceived benefit $(\mathrm{OR}=1.16(95 \%$ $\mathrm{CI}[1.03,1.29] p<0.000)$; perceived barrier $(\mathrm{OR}=0.58,95 \% \mathrm{CI}$ $[0.56,0.67] p<0.000)$ and self-efficacy $(\mathrm{OR}=1.33,95 \% \mathrm{CI}$ $[1.12,1.57] p<0.001)$ were identified as significantly associated $(p<0.05)$ variables with recommended physical activity.

Unit changes in the individual's perception of barriers to physical activity will reduce the likelihood to engage in high-recommended physical activity by 0.58 . In the same way, unit changes in the patient's perception of ability to do recommended physical activity and benefits associated with engaging in physical activity will increase the likelihood of doing it by 1.42 and 1.16 , respectively.

However, variables such as educational status, frequency of information heard, and general knowledge about diabetes and physical activity were not significantly associated in multivariate analysis (Table 2).

\section{Discussion}

This study revealed that, of the 319 DMT-2 patients, $11.9 \%$ engaged in the recommended physical activity. This was similar to studies done in Ethiopia, indicating that regular exercise was the least practiced self-care behavior among

Table 2 Independent predictors of physical activity behavior of patients with diabetes type-2 in Jimma University Specialized Hospital, Southwest Ethiopia, 2013

\begin{tabular}{|c|c|c|c|c|c|c|}
\hline \multirow[t]{2}{*}{ Variables } & \multicolumn{2}{|c|}{ Recommended PA level } & \multirow[t]{2}{*}{ AOR } & \multirow[t]{2}{*}{$95 \% \mathrm{Cl}$} & & \multirow[t]{2}{*}{$P$-value } \\
\hline & High (n) & Low (n) & & & & \\
\hline \multicolumn{7}{|l|}{ Level of education } \\
\hline Illiterate & 2 & 50 & Ref & & & 0.079 \\
\hline Read and write & 6 & 88 & 3.26 & 0.81 & 13.15 & 0.096 \\
\hline Elementary & 5 & 58 & 0.48 & 0.09 & 2.60 & 0.395 \\
\hline Secondary & 12 & 59 & 0.46 & 0.06 & 3.41 & 0.447 \\
\hline Tertiary and above & 13 & 26 & $0.5 \mathrm{I}$ & 0.06 & 4.09 & 0.527 \\
\hline \multicolumn{7}{|l|}{ Occupation } \\
\hline Government employee & 19 & 78 & Ref & & & 0.065 \\
\hline Farmer & 13 & 80 & 0.08 & 0.01 & 0.48 & 0.005 \\
\hline Household & 5 & 60 & 0.23 & 0.04 & 1.19 & 0.079 \\
\hline Merchant & 7 & 30 & 0.58 & 0.11 & 3.01 & 0.518 \\
\hline Others & 4 & 27 & 0.50 & 0.09 & 2.80 & 0.427 \\
\hline \multicolumn{7}{|l|}{ Knowledge of PA } \\
\hline Knowledgeable & 11 & 207 & Ref & & & \\
\hline Not knowledgeable & 27 & 74 & 2.37 & 0.74 & 7.63 & 0.148 \\
\hline \multicolumn{7}{|l|}{ BMI } \\
\hline Normal & 26 & 225 & Ref & & & \\
\hline Above normal & 12 & 56 & 1.59 & 0.51 & 4.93 & 0.421 \\
\hline Self-efficacy & & & 1.33 & 1.12 & 1.57 & 0.001 \\
\hline Perceived benefit of PA & & & 1.16 & 1.03 & 1.29 & 0.011 \\
\hline Perceived barriers to PA & & & 0.58 & 0.50 & 0.67 & 0.000 \\
\hline
\end{tabular}

Note: $P<0.005$ was considered statistically significant.

Abbreviations: $\mathrm{Cl}$, confidence interval; PA, physical activity; AOR, adjusted odds ratio; BMI, body mass index. 
these patients. ${ }^{11}$ But this was different from the study done in United States, which indicated that $39 \%$ were engaged in the recommended physical activity. ${ }^{12,14}$ This difference is due to socio-economic factors and the age of the study participants.

In this study, the educational status was not significantly associated with the likelihood of engaging in the recommended physical activity. However, studies done in Iran and in the southeastern United States metropolitan area showed that education is an important factor and significantly associated with physical activity practice. ${ }^{14}$

The current study found that BMI status affected individual physical exercise behavior, and that BMI has no statistically significant influence on physical activity. This is in accordance with the findings from Ethiopia. ${ }^{11}$ The findings were contrary to those of the study done in Australia and Jordan, where BMI was significantly associated with physical activity adherence; it seemed that the study participants had high BMI, and that the physician recommended physical activity predominantly to manage blood sugar levels. ${ }^{15,16}$

Knowledge is an essential factor for behavior change but it cannot be a sufficient condition to behavior alone. ${ }^{17}$ In this study, knowledge of the respondents about diabetes was very high, accounting for 279 (87.5\%); however, not significantly associated with recommended physical activity practice, which may be due to the interplay of factors beyond it, such as high perceived barriers, less perceived benefit and less self-efficacy as noted in this study. This is again in line with the findings of the study done in Iraq, which reportedly showed that knowledge about diabetes had no statistically significant association with glycemic control and physical activity. ${ }^{14}$

This study revealed that self-efficacy is strongly associated with physical activity among DMT-2 patients. This finding was similar to that of studies done in Iran, United States and Australia, in which a strong predictor of physical activity adherence was self-efficacy. ${ }^{14,18-21}$ This implies that it is conventional that highly efficacious people are more likely to persevere in their attempts to perform a recommended behavior in different situations.

This study revealed that the perceived barriers and perceived benefit were significantly associated with practicing recommended physical activity. These findings were also similar to those of the study done in India. ${ }^{22}$ Diabetes patients who had perception of less barrier and high benefit of recommended physical activity had high tendency to practice the recommended physical activity.

This study revealed that reach and frequency of appropriate message had no significant association with the likelihood of engaging in the recommended physical activity practice. These findings are also echoed in an Ethiopian study, which reported that the frequency of information heard had no significant association with physical activity practice. ${ }^{13}$ However, contrary to the study done in Harar, Ethiopia, a study at JUSH showed that frequency of information heard had significant association with the likelihood of engaging in recommended physical activity. ${ }^{11}$ This may be due to social desirability bias by patients, because the data collectors were health professionals working in the diabetes clinic, and socio-demographic variation between the study groups.

\section{Conclusion}

This study illustrated that DMT-2 patients were not likely to engage in the recommended physical activities. Perceived barrier and perceived benefit associated with physical activity and self-efficacy became potential predictors. None of the socio-demographic factors affect the physical activity behavior of these groups. Diabetes intervention messages should focus on building individual self-efficacy to overcome those barriers with due emphasis to suggested concrete benefit of physical activity.

\section{Acknowledgments}

This work was supported by grants from Jimma University, College of Health Science Ethiopia, for academic purpose. The funders had no impact on design, conduct and reporting of the study; collection, management, analysis and interpretation of the data; and preparation, review or approval of the manuscript.

\section{Author contributions}

All authors contributed toward data analysis, drafting and critically revising the paper and agree to be accountable for all aspects of the work.

\section{Disclosure}

The authors report no conflicts of interests in this work.

\section{References}

1. International Diabetes Federation. IDF Diabetes Atlas. 6th ed. 2013; 55-57.

2. Duarte CK, Almeida JC, Merker AJ, Fde OB, Tda RC. Physical activity level and exercise in patients with diabetes mellitus. Rev Assoc Med Bras s(1992). 2012;58(2):215-221.

3. Sicree R, Shaw J, Zimmet P. The global burden of diabetes and impaired glucose tolerance. IDF Atlas. 2012;4(13):134-149.

4. Yemane T, Belachew T, Asaminew B, Befekadu O. Type-2 diabetes mellitus in Jimma town, southwest Ethiopia. Ethiopia J Health Sci. 2007;17(2):87-93. 
5. Tamiru S, Alemseged F. Risk factors for cardiovascular diseases among diabetic patients in Southwest Ethiopia. Ethiop J Health Sci. 2010;20(2):121-128.

6. Prevett M. Chronic non-communicable diseases in Ethiopia-a hidden burden. Ethiop J Health Sci. 2012;22(S):1-2.

7. Mbanya JC, Motala AA, Sobngwi E, Assah FK, Enoru ST. Diabetes in sub-Saharan Africa. Lancet. 2010;375(9733):2254-2266.

8. Ghazanfari Z, Niknami S, Ghofranipour F, Hajizadeh E, Montazeri A. Development and psychometric properties of a belief-based physical activity questionnaire for diabetic patients (PAQ-DP). BMC Med Res Methodol. 2010;10:104.

9. Daniele TM, Bruin VM, Oliveira DS, Pompeu CM, Forti AC. Associations among physical activity, comorbidities, depressive symptoms and health-related quality of life in type 2 diabetes. Arq Bras Endocrinol Metabol. 2013;57(1):44-50.

10. Fattahi A, Barati M, Bashirian S, Moghadam RH. Physical activity and its related factors among type 2 diabetic patients in Hamadan. Iran J Diabetes Obes. 2014;6(2):85-91.

11. Hailu E, Mariam WH, Belachew T, Birhanu Z. Self-care practice and glycaemic control amongst adults with diabetes at the Jimma University Specialized Hospital in south-west Ethiopia: a cross-sectional study. Afr J Prim Health Care Fam Med. 2012;4(1):311.

12. Morrato EH, Hill JO, Wyatt HR, Ghushchyan V, Sullivan PW. Physical activity in U.S.adults with diabetes and at risk for developing diabetes, 2003. Diabetes Care. 2007;30(2):203-209.

13. Tamirat A, Abebe L, Kirose G. Prediction of physical activity among type-2 diabetes patients attending Jimma University Specialized Hospital, Southwest Ethiopia: application of health belief model. Sci J Public Health. 2014;2(6):524-531.
14. Didarloo AR, Shojaeizadeh D, Gharaaghaji Asl R, Habibzadeh H, Niknami Sh, Pourali R. Prediction of self-management behavior among Iranian women with type 2 diabetes: application of the theory of reasoned action along with self-efficacy (ETRA). Iran Red Crescent Med J. 2012;14(2):86-95.

15. Glanz K, Rimer BK, Viswanath K, editors. Health Behavior and Health Education Theory, Research and Practice. 4th ed. Hoboken, NJ: John Wiley \& Sons; 2008.

16. Rosenstock IM, Strecher VJ, Becker MH. Social learning theory and the health belief model. Health Educ Q. 1988;15(2):175-183.

17. Al-Khawaldeh OA, Al-Hassan MA, Froelicher ES. Self-efficacy, self-management, and glycemic control in adults with type-2 diabetes mellitus. J Diabetes Complications. 2012;26(1):10-16.

18. Chlebowy DO, Myers J, Mendes AN. Socio-demographic variables and self-efficacy in Caucasian and African American adults with type 2 diabetes. South Online J Nurs Res. 2010;10(4):1-13.

19. Critchley CR, Hardie EA, Moore SM. Examining the psychological pathways to behavior change in a group-based lifestyle program to prevent type 2 diabetes. Diabetes Care. 2012;35(4):699-705.

20. Darawad MW, Mosleh S, Khalil AA, Maharmeh M, Hamdan-Mansour AM, Samarkandi OA. Investigating physical exercise among Jordanians with diabetes mellitus. Health. 2016;8(2):181-189.

21. Dutton GR, Tan F, Provost BC, Sorenson JL, Allen B, Smith D. Relationship between self-efficacy and physical activity among patients with type 2 diabetes. J Behav Med. 2009;32(3):270-277.

22. Abraham AM, Sudhir PM, Philip M, Bantwal G. Illness perceptions and perceived barriers to self-care in patients with type 2 diabetes mellitus: an exploratory study from India. Int $J$ Diabetes Dev Ctries. 2015;35(2):137-144.
Journal of Multidisciplinary Healthcare

\section{Publish your work in this journal}

The Journal of Multidisciplinary Healthcare is an international, peerreviewed open-access journal that aims to represent and publish research in healthcare areas delivered by practitioners of different disciplines. This includes studies and reviews conducted by multidisciplinary teams as well as research which evaluates the results or conduct of such teams or health

\section{Dovepress}

care processes in general. The journal covers a very wide range of areas and welcomes submissions from practitioners at all levels, from all over the world. The manuscript management system is completely online and includes a very quick and fair peer-review system. Visit http://www.dovepress.com/ testimonials.php to read real quotes from published authors. 